\title{
Pathologic Stage IA Cutaneous Melanoma AJCC v8
}

National Cancer Institute

\section{Source}

National Cancer Institute. Pathologic Stage IA Cutaneous Melanoma A/CC v8. NCI

Thesaurus. Code C137664.

Stage IA includes: (T1a, N0, M0); (T 1 b, N0, M0). T1a: Tumor measuring less than $0.8 \mathrm{~mm}$ in thickness. Ulceration status: Without ulceration. T1 b: T umor measuring less than 0.8 $\mathrm{mm}$ in thickness with ulceration, or 0.8-1.0 mm with or without ulceration. N0: No regional lymph node metastasis detected. Presence of in-transit, satellite, and/or microsatellite metastases: No. M0: No evidence of distant metastasis. LDH level is not applicable. (AJCC 8th ed.) 